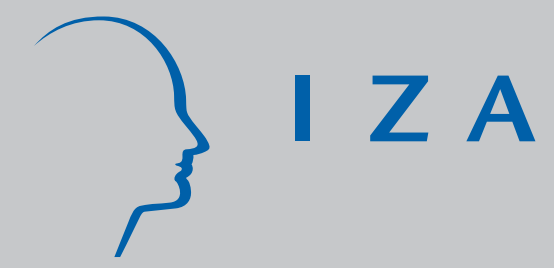

IZA DP No. 1502

Beware of Workaholics: Household Preferences and Individual Equilibrium Utility

Hans Gersbach

Hans Haller

February 2005 


\title{
Beware of Workaholics: Household Preferences and Individual Equilibrium Utility
}

\author{
Hans Gersbach \\ University of Heidelberg \\ and IZA Bonn
}

Hans Haller

Virginia Tech

\section{Discussion Paper No. 1502 \\ February 2005}

\author{
IZA \\ P.O. Box 7240 \\ 53072 Bonn \\ Germany \\ Phone: +49-228-3894-0 \\ Fax: +49-228-3894-180 \\ Email: iza@iza.org
}

\begin{abstract}
Any opinions expressed here are those of the author(s) and not those of the institute. Research disseminated by IZA may include views on policy, but the institute itself takes no institutional policy positions.
\end{abstract}

The Institute for the Study of Labor (IZA) in Bonn is a local and virtual international research center and a place of communication between science, politics and business. IZA is an independent nonprofit company supported by Deutsche Post World Net. The center is associated with the University of Bonn and offers a stimulating research environment through its research networks, research support, and visitors and doctoral programs. IZA engages in (i) original and internationally competitive research in all fields of labor economics, (ii) development of policy concepts, and (iii) dissemination of research results and concepts to the interested public.

IZA Discussion Papers often represent preliminary work and are circulated to encourage discussion. Citation of such a paper should account for its provisional character. A revised version may be available directly from the author. 
IZA Discussion Paper No. 1502

February 2005

\section{ABSTRACT \\ Beware of Workaholics: Household Preferences and Individual Equilibrium Utility*}

This paper analyzes the effects of sociological changes in the form of a shift of influence within two-member households participating in labor and product markets. The most striking effects occur when household members differ in individual preferences and enjoy positive leisure-dependent externalities. For instance, a global sociological change where the "workaholic" member becomes more influential in each working class household can render the working class worse off. A binding restriction on the number of hours an individual is allowed to work can benefit all workers.

JEL Classification: D10, D50, J22

Keywords: household behavior, general equilibrium, externalities, labor supply

Corresponding author:

Hans Gersbach

Department of Economics

University of Heidelberg

Grabengasse 14

69117 Heidelberg

Germany

Email: gersbach@uni-hd.de

\footnotetext{
* We are grateful to Clive Bell, Christoph Schmidt, participants in the 2000 World Congress of the Econometric Society in Seattle, and seminar audiences in Berlin and Heidelberg for their helpful comments.
} 


\section{Introduction}

The labor supply model of Chiappori $(1988,1992)$ is based on collective rationality of households. It provides a convenient framework for empirical analysis, as substantiated most recently by Chiappori, Fortin and Lacroix (2002). In the present paper, we embed this labor supply model in a general equilibrium model, and examine how sociological changes in the form of increased influence of certain (small or large) groups of individuals within their households can affect the equilibrium allocation and welfare of all the individuals in all the households.

We distinguish between two goods: labor (leisure) and a composite consumption good. Individuals are endowed with leisure, part of which they consume, and part of which they supply to the labor market. Labor is demanded by a production sector that produces the composite consumption good.

This modeling approach has several motivations and justifications. It demonstrates how one can perform general equilibrium analysis with a model of the household that is close to Chiappori's and the empirical literature. It also demonstrates that our previous analysis can be extended to economies with production. ${ }^{1}$ Further, our current analysis shows that spillovers between households are not necessarily mitigated by the presence of a production sector. Moreover, it discovers new effects in the presence of a production sector. Finally, introducing labor and a pure consumption good allows us to distinguish between workaholic and hedonistic household members who differ in their marginal rate of substitution between leisure and the composite consumption good.

\footnotetext{
${ }^{1}$ Gersbach and Haller (2001) and Haller (2000) incorporate collective rationality à la Chiappori $(1988,1992)$ into general equilibrium models of a pure exchange economy with multi-member households.
} 
Having labor as a factor of production allows us to differentiate between labor and capital income. For most of the analysis, we distinguish between a working class and a leisure class. The working class members receive only labor income, and form the two-person households under consideration. The leisure class members receive all capital income and no labor income. Their consumer and household characteristics are not specified further. Instead of a leisure class, we can also have a government that absorbs all profits without affecting household decisions.

Our first central result is that workaholics are bad company. If the workaholic in a household gains more influence, the partner is induced to work more and consume less, whereas the workaholic tends to work less and consume more. Moreover, through the labor market, the workaholic causes negative spillovers to the members of other households, both workaholics and hedonists. The severity of these spillovers depends on the nature of externalities within the households. Perhaps the most striking result is that a global sociological change where the workaholic member becomes more influential in each working class household can render the entire working class worse off - with the leisure class as the sole beneficiary. A similar effect cannot happen in a model without production or with the production sector fully owned by the working class.

Our second important finding is that a binding restriction on the number of hours an individual is allowed to work can benefit all workers, those for whom the restriction is binding and those for whom it is not.

Our findings can be used to explain and assess trends regarding the length of the work that began to emerge in industrialized countries in recent decades. As we will elaborate in detail in section 6, our analysis may for instance explain why there have been strong attempts to reduce the regular work week in Europe and why compensation schemes of high-skilled employees 
who work long hours are partially based on firm performance.

In the next section, we introduce some of the main features of consumers, households, and the production sector or industry. In Section 3, we present and analyze the basic general equilibrium framework with fixed (leisureindependent) externalities within households. In Section 4, we consider the equilibrium effects of local (global) sociological changes which lead to a growing influence of the workaholic member of a household (members of households). Section 5 comprises three model variations: introduction of a particular form of variable (leisure-dependent) externalities; introduction of binding exogenous restrictions on individual labor supply; introduction of industry ownership by working class households. In Section 6 we relate our results to current trends of working hours in industrial countries. Section 7 concludes.

\section{Composition of Society and the Economy}

We consider an economy composed of finitely many households $h=1, \ldots, n$, with $n \geq 2$. Household $h$ has two members $h_{1}$ and $h_{2}$, called the first member and the second member, respectively. The members of all $n$ households form a population $I$ of size $2 n$. There are two goods: leisure and a private Hicksian composite good whose price $p$ is normalized to unity. Consumption of $h_{i}$, the $i$ th member of household $h$, consists of his composite good consumption, denoted by $c_{i}^{h}$, and his consumption of leisure, denoted by $T-l_{i}^{h}$ where $T$ denotes the total time available to each individual and $l_{i}^{h}$ denotes $i$ 's labor supply. The resource constraints and the assumption of interior solutions imply that:

$$
c_{i}^{h}>0 \quad \text { and } \quad 0<l_{i}^{h}<T, \quad i=1,2 .
$$


Utility of individual $h_{i}$ is given by:

$$
U_{i}^{h}:=k_{i} \ln c_{i}^{h}+\left(1-k_{i}\right) \ln \left(T-l_{i}^{h}\right)+G_{i}^{h}\left(l_{i}^{h}, l_{j}^{h}\right)
$$

The coefficient $k_{i} \in(0,1)$ represents the weight of the physical consumption good relative to leisure. The term $G_{i}^{h}\left(l_{i}^{h}, l_{j}^{h}\right)$ represents a group externality experienced by individual $h_{i}$, i.e., the emotional benefit of individual $h_{i}$ from living together with individual $h_{j}, j \neq i$. Household members can differ with respect to the weights $k_{i}$ and, of course, with respect to the group externality $G_{i}^{h}\left(l_{i}^{h}, l_{j}^{h}\right)$.

When $k_{1}>k_{2}$, we call the first household members "workaholics" and the second household members "hedonists". Often the term "workaholic" describes simply a person with a strong work ethic or an addiction to or obsession for work. Our notion captures more sophisticated behavior. As an autonomous consumer facing a given real wage rate, the workaholic would work more and consume more of the composite commodity than the autonomous hedonist. As a household member (with a lot of weight in the household's utilitarian decision rule) the workaholic may actually end up working less and consuming more than the hedonistic partner. Thus, without knowing their respective influence on household decisions, an outside observer might mistake the workaholic for the hedonist, and vice versa.

We will consider two plausible cases of group externalities: first, when the emotional benefit from being together with a partner is fixed, and second, when the group externality depends on the leisure time or access time of the other household member. ${ }^{2}$

Several remarks about the nature of preferences are in order. The most natural assumption, which will be pursued in section five, is variable exter-

\footnotetext{
${ }^{2}$ Note that if the group externality depends on the leisure time of the other household member, individual decisions about working and leisure time would not be efficient for the household.
} 
nalities where the individual's benefit of human relationships is increasing in the leisure time the partner can offer. Intuitively, the emotional benefit in partnerships depend on time individuals have to share and to communicate. If such externalities are quite strong, households will tend to synchronize their leisure time. The synchronization of working or leisure schedules in the presence of externalities has received widespread attention in other contexts such as interaction of workers in production facilities (see Weiss (1996)) and liberalization of shop-closing laws where the theory has been developed by Clemenz (1990) and Burda and Weil (1999) (see also Putnam (1995)).

In our model there are two sources of externalities. First, non- pecuniary externalities, i.e. group externalities, occur only at the household level and are internalized by efficient collective decisions within households. As we will discuss in detail in subsection 5.3., the presence of such household specific group externalities do not destroy Pareto-efficiency of competitive markets. Second, when we discuss local and global changes of bargaining power in households, pecuniary externalities arise which do not destroy the validity of the first welfare theorem either, but can make entire classes of the society worse off.

Except in subsection 5.3, we assume that the households under consideration only receive wage income. The income from holding shares of firms is assumed to accrue to individuals who are not part of the population $I$ we are studying. This is justified by the fact that the majority of households primarily depend on the wage income. We also assume that shareholders do not participate in the labor market. There are several conceivable scenarios for the existence of such a "leisure class". One is that the shareholders live on another island, continent, or planet. Another one is that at the prevailing wages, shareholders prefer not to work. A third one is that the shareholders are retirees who are unable to work and own shares directly or indirectly 
through pension funds. Yet another alternative is that the government imposes a $100 \%$ profit tax and spends the tax revenue on pensions or in other wasteful, harmful, or useful ways that do not affect household decisions, an assumption often made in the literature on optimal taxation [see, e.g., Auerbach (1985)]. The government might also own the industry and thus be the recipient of all profits. But then the assumption of profit maximization and perfect competition is less convincing. Obviously, a convex combination of all these alternatives is quite possible. Whoever ends up with some of the profits uses this income solely for the purchase of the composite good.

The production sector is assumed to be perfectly competitive. Since we are not concerned with the distributive aspects of share ownership, it suffices to determine aggregate profits using the aggregate technology, which is represented by a production function. The production function is of a specific functional form with standard properties and convenient numerical features.

\section{Equilibrium with Fixed Externalities}

In this section we assume fixed externalities, that is $G_{i}^{h}\left(l_{i}^{h}, l_{j}^{h}\right)=\bar{G}_{i}^{h}$. Since externalities are fixed, household optimization will be equivalent to the absence of externalities.

\subsection{Household Decisions}

The utility of household $h$ is given by:

$$
U^{h}:=\alpha U_{1}^{h}+(1-\alpha) U_{2}^{h}
$$


where $\alpha \in(0,1)$ is the utilitarian power or weight of the first individual in the household utility function. Note that, for the time being, we assume that households only earn income from wages, and hence industry shareholders do not belong to the set of households under consideration. Therefore, the budget constraint amounts to:

$$
c_{1}^{h}+c_{2}^{h}=w\left(l_{1}^{h}+l_{2}^{h}\right)
$$

where $w$ denotes the wage rate. The Lagrangian for the household's optimization problem is given by

$$
\begin{aligned}
\mathcal{L}= & \alpha\left(k_{1} \ln c_{1}^{h}+\left(1-k_{1}\right) \ln \left(T-l_{1}^{h}\right)+\bar{G}_{1}^{h}\right) \\
& +(1-\alpha)\left(k_{2} \ln c_{2}^{h}+\left(1-k_{2}\right) \ln \left(T-l_{2}^{h}\right)+\bar{G}_{2}^{h}\right) \\
& -\lambda\left(c_{1}^{h}+c_{2}^{h}-w\left(l_{1}^{h}+l_{2}^{h}\right)\right) .
\end{aligned}
$$

The first-order conditions amount to:

$$
\begin{aligned}
\frac{\partial \mathcal{L}}{\partial c_{1}^{h}} & =\frac{\alpha k_{1}}{c_{1}^{h}}-\lambda=0, \\
\frac{\partial \mathcal{L}}{\partial c_{2}^{h}} & =\frac{(1-\alpha) k_{2}}{c_{2}^{h}}-\lambda=0, \\
\frac{\partial \mathcal{L}}{\partial l_{1}^{h}} & =\frac{-\alpha\left(1-k_{1}\right)}{T-l_{1}^{h}}+\lambda w=0, \\
\frac{\partial \mathcal{L}}{\partial l_{2}^{h}} & =\frac{-(1-\alpha)\left(1-k_{2}\right)}{T-l_{2}^{h}}+\lambda w=0, \\
\frac{\partial \mathcal{L}}{\partial \lambda} & =w\left(l_{1}^{h}+l_{2}^{h}\right)-\left(c_{1}^{h}+c_{2}^{h}\right)=0 .
\end{aligned}
$$

The budget constraint and the first-order conditions imply

$$
\frac{c_{1}^{h}+c_{2}^{h}}{l_{1}^{h}+l_{2}^{h}}=\frac{\left(\alpha k_{1}+(1-\alpha) k_{2}\right) w}{\alpha k_{1}+(1-\alpha) k_{2}+2 \lambda T w-1}=w
$$

which yields

$$
\lambda=\frac{1}{2 w T}
$$


Replacing $\lambda$ in equations (3) - (6), we obtain the optimal individual consumption and labor supply:

$$
\begin{aligned}
c_{1}^{h} & =2 \alpha k_{1} w T, \\
c_{2}^{h} & =2(1-\alpha) k_{2} w T, \\
l_{1}^{h} & =2\left(\frac{1}{2}-\alpha\left(1-k_{1}\right)\right) T, \\
l_{2}^{h} & =2\left(\frac{1}{2}-(1-\alpha)\left(1-k_{2}\right)\right) T .
\end{aligned}
$$

For simplicity, we have not explicitly imposed non-negativity constraints on labor supply. Let us assume instead that $\alpha\left(1-k_{1}\right)<1 / 2$, and $(1-\alpha)(1-$ $\left.k_{2}\right)<1 / 2$, so that the constraints are not binding. These assumptions will have to be suitably modified in Section 5 .

Total labor supply of a household is given by:

$$
l_{1}^{h}+l_{2}^{h}=2 T\left(\alpha k_{1}+(1-\alpha) k_{2}\right) .
$$

Note that total labor supply depends linearly on $k_{1}$ and $k_{2}$ and the utilitarian power of each individual. A proportional increase of the weight of consumption relative to leisure for both individuals will increase total labor supply by the same proportion.

\subsection{Equilibrium in the Labor Market with Homogeneous Households}

For the moment we make the additional assumption that all households are homogeneous with respect to the preferences of their members and household utility.

Total labor supply of the economy $L^{s}$ is given by:

$$
L^{s}:=\sum_{h=1}^{n}\left[l_{1}^{h}+l_{2}^{h}\right]=n\left(l_{1}^{h}+l_{2}^{h}\right)=2 \operatorname{Tn}\left(\alpha k_{1}+(1-\alpha) k_{2}\right) .
$$


Let $f(L)=\beta \ln (1+L)$. The first order condition for profit maximization yields

$$
w=\frac{\beta}{1+L^{s}}=\frac{\beta}{1+2 n\left(\alpha k_{1}+(1-\alpha) k_{2}\right) T} .
$$

Substituting this equilibrium value for $w$ in equations (8) - (11), we obtain the optimal consumption and labor input of household members:

$$
\begin{aligned}
c_{1}^{h} & =\frac{\alpha k_{1} \beta}{1 /(2 T)+n\left(\alpha k_{1}+(1-\alpha) k_{2}\right)}, \\
c_{2}^{h} & =\frac{(1-\alpha) k_{2} \beta}{1 /(2 T)+n\left(\alpha k_{1}+(1-\alpha) k_{2}\right)}, \\
l_{1}^{h} & =2\left(\frac{1}{2}-\alpha\left(1-k_{1}\right)\right) T, \\
l_{2}^{h} & =2\left(\frac{1}{2}-(1-\alpha)\left(1-k_{2}\right)\right) T, \\
l_{1}^{h}+l_{2}^{h} & =2 T\left(\alpha k_{1}+(1-\alpha) k_{2}\right) .
\end{aligned}
$$

\section{Sociological Changes}

Here we study the allocative and welfare consequences of a shift of the utilitarian welfare weights within households reflecting the increased relative importance or power of the first household member. By a global change we mean that the utilitarian welfare weight changes in all households. A local change describes the change of the utilitarian weight in one household.

\subsection{Global Changes}

We first discuss how identical changes of $\alpha$ across all households affect individuals and households. It follows immediately from (13)-(16) that as $\alpha$ increases, the first household member consumes more and works less while the second household member consumes less and works more. Hence first 
household members are clear gainers and second household members are clear losers from such a global sociological change.

\subsection{Local Changes}

In the following, we examine how bargaining power changes in some households affect the utility of individuals in other households where bargaining power remains unchanged. Let us assume that in $s$ of the households, denoted $h^{*}$, the first individual has a weight factor $\alpha=\alpha^{*}$ and in $n-s$ of the households, denoted $h_{*}$, the individual has a weight factor $\alpha=\alpha_{*}$, where $\alpha^{*}>\alpha_{*}$. This is a departure from the homogeneity assumption made in 3.2. Without loss of generality, we also assume that $k_{1}>k_{2}$, and thus that the first household member is more willing to sacrifice leisure time for income and consumption of commodities. We therefore call the first member the workaholic and the second member the hedonist.

For the total labor input we obtain

$$
\begin{aligned}
L & =\sum_{h=1}^{s} l_{1}^{h^{*}}+l_{2}^{h^{*}}+\sum_{h=s+1}^{n} l_{1}^{h_{*}}+l_{2}^{h_{*}} \\
& =2 T\left(s\left(\alpha^{*} k_{1}+\left(1-\alpha^{*}\right) k_{2}\right)+(n-s)\left(\alpha_{*} k_{1}+\left(1-\alpha_{*}\right) k_{2}\right)\right) \\
& =2 T\left(s\left(\alpha^{*}-\alpha_{*}\right)\left(k_{1}-k_{2}\right)+n\left(\alpha_{*} k_{1}+\left(1-\alpha_{*}\right) k_{2}\right)\right)
\end{aligned}
$$

and therefore

$$
w=\frac{\beta}{1+2 T\left(s\left(\alpha^{*}-\alpha_{*}\right)\left(k_{1}-k_{2}\right)+n\left(\alpha_{*} k_{1}+\left(1-\alpha_{*}\right) k_{2}\right)\right)} .
$$

Hence:

- For $h=h^{*}$, we get

$$
\begin{aligned}
c_{1}^{h} & =\frac{\alpha^{*} k_{1} \beta}{1 /(2 T)+\left(s\left(\alpha^{*}-\alpha_{*}\right)\left(k_{1}-k_{2}\right)+n\left(\alpha_{*} k_{1}+\left(1-\alpha_{*}\right) k_{2}\right)\right.}, \\
c_{2}^{h} & =\frac{\left(1-\alpha^{*}\right) k_{2} \beta}{1 /(2 T)+\left(s\left(\alpha^{*}-\alpha_{*}\right)\left(k_{1}-k_{2}\right)+n\left(\alpha_{*} k_{1}+\left(1-\alpha_{*}\right) k_{2}\right)\right.},
\end{aligned}
$$




$$
\begin{aligned}
& l_{1}^{h}=2\left(\frac{1}{2}-\alpha^{*}\left(1-k_{1}\right)\right) T \\
& l_{2}^{h}=2\left(\frac{1}{2}-\left(1-\alpha^{*}\right)\left(1-k_{2}\right)\right) T .
\end{aligned}
$$

- For $h=h_{*}$, we get

$$
\begin{aligned}
c_{1}^{h} & =\frac{\alpha_{*} k_{1} \beta}{1 /(2 T)+\left(s\left(\alpha^{*}-\alpha_{*}\right)\left(k_{1}-k_{2}\right)+n\left(\alpha_{*} k_{1}+\left(1-\alpha_{*}\right) k_{2}\right)\right.}, \\
c_{2}^{h} & =\frac{2\left(1-\alpha_{*}\right) k_{2} \beta}{1 /(2 T)+\left(s\left(\alpha^{*}-\alpha_{*}\right)\left(k_{1}-k_{2}\right)+n\left(\alpha_{*} k_{1}+\left(1-\alpha_{*}\right) k_{2}\right)\right.}, \\
l_{1}^{h} & =2\left(\frac{1}{2}-\alpha_{*}\left(1-k_{1}\right)\right) T, \\
l_{2}^{h} & =2\left(\frac{1}{2}-\left(1-\alpha_{*}\right)\left(1-k_{2}\right)\right) T .
\end{aligned}
$$

This gives rise to unambiguous comparative statics for part of which we shall temporarily treat $s$ as a continuous variable:

Proposition 1 Suppose $\alpha^{*}>\alpha_{*}$ and $k_{1}>k_{2}$. Then

$$
\frac{\partial w}{\partial s}<0 \text { and } \frac{\partial U_{1}^{h^{*}}}{\partial s}<0, \frac{\partial U_{2}^{h^{*}}}{\partial s}<0, \frac{\partial U_{1}^{h_{*}}}{\partial s}<0, \frac{\partial U_{1}^{h_{*}}}{\partial s}<0
$$

where $h^{*}$ and $h_{*}$ are households whose internal balance of power remains unchanged.

PROOF.

$$
\begin{aligned}
\frac{\partial w}{\partial s} & =-\frac{2 T \beta\left(\alpha^{*}-\alpha_{*}\right)\left(k_{1}-k_{2}\right)}{\left[1+2 T\left(s\left(\alpha^{*}-\alpha_{*}\right)\left(k_{1}-k_{2}\right)+n\left(\alpha_{*} k_{1}+\left(1-\alpha_{*}\right) k_{2}\right)\right)\right]^{2}}<0, \\
\frac{\partial U_{1}^{h^{*}}}{\partial s} & =-\frac{k_{1}\left(\alpha^{*}-\alpha_{*}\right)\left(k_{1}-k_{2}\right)}{1 /(2 T)+\left(s\left(\alpha^{*}-\alpha_{*}\right)\left(k_{1}-k_{2}\right)+n\left(\alpha_{*} k_{1}+\left(1-\alpha_{*}\right) k_{2}\right)\right.}<0,
\end{aligned}
$$

etc.

The proposition implies that the increase of relative importance or power of a workaholic in one household negatively affects all other individuals in the 
working population. Workaholics and hedonists in other households equally dislike an increase of the bargaining power of the workaholic in the particular household under consideration. An intuitive explanation would be that the shift of bargaining power increases (decreases) the labor supply of the workaholic (hedonist) in that household, but the net effect is positive. The latter conclusion follows from the fact that the household's total labor supply is proportional to $\alpha k_{1}+(1-\alpha) k_{2}$ which increases when $\alpha$ rises. In turn, a higher labor supply lowers wages and, consequently, the utility in all other households in population $I$.

While the net labor supply effect in a particular household is correctly predicted by the preceding intuitive argument, the details are quite different from what intuition suggests. Namely, the situation turns out to be worse for the hedonist in that household, who suffers from both a lower wage rate and a loss of bargaining power. The hedonist works more and consumes less than before, while the workaholic actually works less and consumes more, as an explicit comparison shows. Furthermore, since the wage rate has declined, industry profits are higher in the new equilibrium and, therefore, the shareholders (the leisure class) or the government gain from the shift of bargaining power.

To refine intuition, let us compare labor supply terms (10) and (11), and see who actually works more in a household, the workaholic or the hedonist. The workaholic works more than the hedonist when both households members are equally important or powerful, that is when $\alpha=1 / 2$. However, an increase of $\alpha$ leads to a reduction of the workaholic's labor supply, which is more than compensated by an increase of the hedonist's labor supply. At $\alpha=\left(1-k_{2}\right) /\left(2-k_{1}-k_{2}\right)$, both supply the same amount of labor. 
The main findings of this section can be summarized as

Proposition 2 Suppose fixed externalities. Then:

(i) A global shift of power within households towards the workaholic members benefits those members and harms their hedonistic partners.

(ii) A local shift of power within a particular household towards the workaholic member is beneficial to this individual and harms all other consumers in $I$.

We have seen that an increased weight of workaholics in household decisions proves detrimental to the welfare of others. In fact, the presence of workaholics per se is harmful to others. If instead of becoming more influential, the first household member becomes more of a workaholic, the comparative statics results with respect to other individuals are qualitatively the same. Ceteris paribus, the person who becomes a greater workaholic, works more and consumes more of the composite good. The only effect on others is through a reduced wage rate and, consequently, reduced composite good consumption. Needless to say that for the person whose preferences have changed, a comparison of ex ante and ex post welfare is meaningless, unless consumption of the composite good and consumption of leisure move in the same direction. To the extent that the latter condition holds, more pronounced workaholism, or a larger number of workaholics, can be detrimental to the entire work-force. In Section 6, we relate this observation to the phenomenon of prolonged work weeks in some expanding service industries. 


\section{Ramifications}

In this section, we gain additional insights from considering three different variations of the basic model studied thus far. First, we introduce a particular form of variable externalities. Second, we investigate the implications of binding exogenous restrictions on individual labor supply. Third, we address the case in which the households under scrutiny own the industry.

\subsection{Variable Externalities}

In this section we assume variable externalities of the form $G_{i}^{h}\left(l_{i}^{h}, l_{j}^{h}\right)=$ $g_{i}^{h} \ln \left(T-l_{j}^{h}\right)$ with $g_{i}^{h}>0$ for each household $h$ and $i, j \in\{1,2\}, i \neq j$. Such variable group externalities take into account that the benefits of human partnerships can depend on the partner as well as on the leisure time that the partner can offer. ${ }^{3}$

After renormalizing coefficients so that they add up to unity, the utility of household member 1 and 2 , respectively, is given by

$$
\begin{aligned}
& \hat{U}_{1}^{h}=\hat{k}_{1} \ln c_{1}^{h}+\left(1-\hat{k}_{1}-\hat{g}_{1}^{h}\right) \ln \left(T-l_{1}^{h}\right)+\hat{g}_{1}^{h} \ln \left(T-l_{2}^{h}\right), \\
& \hat{U}_{2}^{h}=\hat{k}_{2} \ln c_{2}^{h}+\left(1-\hat{k}_{2}-\hat{g}_{2}^{h}\right) \ln \left(T-l_{2}^{h}\right)+\hat{g}_{2}^{h} \ln \left(T-l_{1}^{h}\right) .
\end{aligned}
$$

The utility of household $h$ is given by

$$
U^{h}=\hat{\alpha} \hat{U}_{1}^{h}+(1-\hat{\alpha}) \hat{U}_{2}^{h}
$$

where $\hat{k}_{i}=k_{i} /\left(1+g_{i}^{h}\right), \hat{g}_{i}^{h}=g_{i}^{h} /\left(1+g_{i}^{h}\right)$,

and $\hat{\alpha}=\alpha\left(1+g_{1}^{h}\right) /\left[\alpha\left(1+g_{1}^{h}\right)+(1-\alpha)\left(1+g_{2}^{h}\right)\right]$.

\footnotetext{
${ }^{3} \mathrm{~A}$ further possibility could be that the externalities depend on the time household members can spend together, that is on the minimum of the individual leisure times. The qualitative behavior of this type of externality is quite similar to the variable externalities studied next, but more cumbersome to analyze.
} 
For homogeneous households an analysis similar to the derivations in 3.1 and 3.2 yields:

$$
w=\frac{\beta}{1+2 n\left(\hat{\alpha} \hat{k}_{1}+(1-\hat{\alpha}) \hat{k}_{2}\right) T}
$$

and

$$
\begin{aligned}
c_{1}^{h} & =2 \hat{\alpha} \hat{k}_{1} w T=\frac{\hat{\alpha} \hat{k}_{1} \beta}{1 /(2 T)+n\left(\hat{\alpha} \hat{k}_{1}+(1-\hat{\alpha}) \hat{k}_{2}\right)}, \\
c_{2}^{h} & =2(1-\hat{\alpha}) \hat{k}_{2} w T=\frac{(1-\hat{\alpha}) \hat{k}_{2} \beta}{1 /(2 T)+n\left(\hat{\alpha} \hat{k}_{1}+(1-\hat{\alpha}) \hat{k}_{2}\right)}, \\
l_{1}^{h} & =2\left(\frac{1}{2}-\hat{g}_{2}^{h}(1-\hat{\alpha})-\hat{\alpha}\left(1-\hat{k}_{1}-\hat{g}_{1}^{h}\right)\right) T \\
& =2\left(\frac{1}{2}-\hat{g}_{2}^{h}-\hat{\alpha}\left(1-\hat{k}_{1}-\hat{g}_{1}^{h}-\hat{g}_{2}^{h}\right)\right) T, \\
l_{2}^{h} & =2\left(\frac{1}{2}-\hat{g}_{1}^{h} \hat{\alpha}-(1-\hat{\alpha})\left(1-\hat{k}_{2}-\hat{g}_{2}^{h}\right)\right) T \\
& =2\left(\frac{1}{2}-\left(1-\hat{k}_{2}-\hat{g}_{2}^{h}\right)+\hat{\alpha}\left(1-\hat{k}_{2}-\hat{g}_{1}^{h}-\hat{g}_{2}^{h}\right)\right) T .
\end{aligned}
$$

With regard to comparative statics, we observe that $\hat{\alpha}$ is increasing in $\alpha$, so that it suffices to study the response to an increase in $\hat{\alpha}$ rather than $\alpha$. We are going to elaborate on two of four conceivable cases. The other two can be analyzed in a similar way.

Case 1: If $\hat{k}_{1}>\hat{k}_{2}$ and $\hat{k}_{1}+\hat{g}_{1}^{h}+\hat{g}_{2}^{h}<1$, then the situation is parallel to that of section 3. A global increase of $\alpha$ benefits first household members and harms second household members. As for the effect of a local sociological change, if $\alpha$ increases only in household $h$, then the first member of household $h$ is the only beneficiary and all other members of population $I$ are negatively affected.

Case 2: If $\hat{k}_{1}>\hat{k}_{2}$ and $\hat{k}_{1}+\hat{g}_{1}^{h}+\hat{g}_{2}^{h}>1$, then a global increase of $\alpha$ has the 
opposite effects on first household members: Their equilibrium consumption of the composite good goes up while their labor supply also goes up. We claim that the net effect on their welfare can be negative. To verify this claim, let us consider the equilibrium utilities, for convenience suppressing the $\wedge$ 's momentarily. We get

$$
\begin{aligned}
U_{1}^{h}= & k_{1} \ln \left(\frac{\alpha k_{1} \beta}{n\left(\alpha k_{1}+(1-\alpha) k_{2}\right)+\frac{1}{2 T}}\right) \\
& +\left(1-k_{1}-g_{1}^{h}\right) \ln \left(2 T\left(g_{2}^{h}(1-\alpha)+\alpha\left(1-k_{1}-g_{1}^{h}\right)\right)\right) \\
& +g_{1}^{h} \ln \left(2 T\left(g_{1}^{h} \alpha+(1-\alpha)\left(1-k_{2}-g_{2}^{h}\right)\right)\right)
\end{aligned}
$$

Differentiating $U_{1}^{h}$ with respect to $\alpha$ yields:

Proposition 3 The equilibrium utility of first household members satisfies

$$
\begin{aligned}
\frac{\partial U_{1}^{h}}{\partial \alpha}= & \frac{g_{1}^{h}\left(-1+g_{1}^{h}+g_{2}^{h}+k_{2}\right)}{(1-\alpha)\left(1-g_{1}^{h}-g_{2}^{h}-k_{2}\right)+g_{1}^{h}} \\
& +\frac{\left(1-g_{1}^{h}-k_{1}\right)\left(1-g_{1}^{h}-g_{2}^{h}-k_{1}\right)}{\alpha\left(1-g_{1}^{h}-g_{2}^{h}-k_{1}\right)+g_{2}^{h}} \\
& +\frac{k_{1}}{\alpha}-\frac{n k_{1}\left(k_{1}-k_{2}\right)}{n\left(\alpha k_{1}+(1-\alpha)\right) k_{2}+\frac{1}{2 T}} .
\end{aligned}
$$

Proposition 3, which merely describes $\frac{\partial U_{1}^{h}}{\partial \alpha}$ indicates that general equilibrium feedbacks interact in a complex way with the local gain in utility when a member of a household can increase its utility by raising its utilitarian power. In the following, we will explore this relationship for special parameter values which imply $\frac{\partial U_{1}^{h}}{\partial \alpha}<0$. In particular, suppose that $k_{2}$ is very small, $T$ is sufficiently large, and $g_{1}^{h}=g_{2}^{h}=: g$ for all $h$. Then we obtain approximately:

$$
\begin{aligned}
\frac{\partial U_{1}^{h}}{\partial \alpha} \approx & \frac{g(-1+2 g)}{(1-\alpha)(1-2 g)+g} \\
& +\frac{\left(1-g-k_{1}\right)\left(1-2 g-k_{1}\right)}{\alpha\left(1-2 g-k_{1}\right)+g} .
\end{aligned}
$$


where we have used that

$$
\frac{k_{1}}{\alpha}-\frac{n k_{1}\left(k_{1}-k_{2}\right)}{n\left(\alpha k_{1}+(1-\alpha)\right) k_{2}+\frac{1}{2 T}} \approx 0 .
$$

If, in addition, $g+k_{1}$ is sufficiently close to one, the second term can be neglected. If, moreover, $g<1 / 2$, the first term is negative and therefore $\partial U_{1}^{h} / \partial \alpha<0$. Therefore, an increase in relative importance or power harms the first household member. This validates our claim.

Let us first discuss the assumptions made during the proof of the claim and then try to assess the result. We now return to the $\wedge$-notation with re-normalized utility coefficients. Then, $\hat{g}_{1}^{h}=\hat{g}_{2}^{h}=\hat{g}$ corresponds to $g_{1}^{h}=$ $g_{2}^{h}=: g$, with $\hat{g}=g /(1+g)$. The condition $\hat{g}<1 / 2$ amounts to $g<1$, which means that the externality is less important than the own commodity consumption and leisure consumption combined. By choosing $g$ and $k_{1}$ close to one, one obtains $\hat{g}+\hat{k}_{1}$ close to one. A very small $k_{2}$ yields a very small $\hat{k}_{2}$. Hence, the conditions are met if both the workaholic and the hedonistic trait are very pronounced and the externality is almost as important as consumption of the composite good and leisure combined.

Compared with an increase of $\alpha$ in (1), an increase of $\hat{\alpha}$ in (18) has two additional effects: The leisure term $\hat{g}_{1}^{h} \ln \left(T-l_{2}^{h}\right)$ weighs more heavily on the household's objective function, whereas the leisure term $\hat{g}_{2}^{h} \ln \left(T-l_{1}^{h}\right)$ has less weight. This is immediately reflected in the first member's optimal labor supply. Without the variable externality, the dependence on $\alpha$ assumes the form $-\alpha\left(1-k_{1}\right)$ in $(10)$. With the variable externality, the dependence on $\hat{\alpha}$ takes the form $-\hat{\alpha}\left(1-\hat{k}_{1}-\hat{g}_{1}^{h}-\hat{g}_{2}^{h}\right)$ in $(21)$. Under the assumptions made to demonstrate the claim, the latter equals approximately $\hat{\alpha} / 2$. Hence, if workaholism is very pronounced and the externalities are strong, but not too strong, then an increase of $\hat{\alpha}$ has a strong positive effect on the first household member's labor supply. ${ }^{4}$

${ }^{4}$ Too strong externalities would imply a low labor supply and fairly large leisure con- 
Notice that for $\hat{g}_{1}^{h}<1 / 2, \hat{g}_{2}^{h}<1 / 2$ and sufficiently small $\hat{k}_{2}, 1-\hat{g}_{1}^{h}-\hat{g}_{2}^{h}-$ $\hat{k}_{2}>0$ holds. If so, the second members' labor supply goes up, while their composite good consumption goes down in response to an increase of $\hat{\alpha}$. Thus there exist model parameter values such that a global shift of power or priorities within households makes everyone in population $I$ worse off.

With respect to a local sociological change, say in household $h$, an increase of $\hat{\alpha}$ from $\hat{\alpha}_{*}$ to $\hat{\alpha}^{*}$ harms all members of population $I$ not belonging to household $h$. If again $1-\hat{g}_{1}^{h}-\hat{g}_{2}^{h}-\hat{k}_{2}>0$, then the second member of household $h$ will be harmed as well. The change can be detrimental to the first household member's welfare, too. The easiest way to arrive at this conclusion is to consider ceteris paribus an increase in $n$. The labor supply effect for the individual is independent of $n$. But the wage effect and, hence, the effect on this individual's composite good consumption, becomes arbitrarily small as $n$ goes to infinity. Hence, for sufficiently large $n$, the net effect of a given change from $\hat{\alpha}_{*}$ to $\hat{\alpha}^{*}$ on the first household member's utility is negative. Therefore, there are model parameter values such that a local shift of power or priorities within a household makes everyone in population $I$ worse off. Our main findings here can be summarized as

Proposition 4 Suppose variable externalities. Then assertions (i) and (ii) of Proposition 2 continue to hold for certain model parameter values. But there exist also model parameter values such that a global or local shift of power within households towards the workaholic member(s) is harmful to all consumers in $I$.

A comparison of Propositions 2 and 4 shows that the comparative statics results are sensitive to the nature of externalities. The striking result of Proposition 4, that all consumers in $I$ can be worse off with higher $\alpha$, means sumption to begin with. This would translate into a small marginal utility of leisure so that the strong positive labor supply response causes only a weak negative welfare effect. 
that equilibrium outcomes for different $\alpha$ can be Pareto-ranked as far as population $I$ is concerned. This fact is not surprising, since profits are not distributed to these consumers and, therefore, the model of the economy is not closed. Walras Law is violated, and the first welfare theorem cannot be established if welfare analysis is restricted to population $I$. But the welfare theorem holds, once shareholders and the government are included. In particular, shareholders or the government gain when all consumers in $I$ lose.

\subsection{Restrictions on Labor Supply}

Germany, by way of some collective bargaining agreements, and France, by recent law, have seen reductions of the regular work week to 35 hours to increase the leisure time of the working class population. A further important argument for these reductions has been that a given amount of work would be distributed among more workers and, thus, unemployment would be lower. ${ }^{5}$

There is full employment in our model. So unemployment is not at issue here. The implications of restrictions on labor supply are of great interest nevertheless as we can examine whether more leisure is beneficial for the working class. Moreover, in section 6 we comment how we can account for unemployment.

We have seen that more importance or power of workaholics induces worka-

\footnotetext{
${ }^{5}$ The employment effects of such work week restrictions, if any, have been modest and ambiguous. The empirical evidence tends to reject the idea that reducing work hours will help to decrease unemployment (see Börsch-Supan (2003), Entorf, König and Pohlmeier (1992), Hunt (1998)). Possibly, the hourly productivity and hourly wage of those employed went up. Since many of the indirect labor costs, like mandatory employer health insurance contributions, are independent of hours worked and wages paid, the full cost of employment per hour increased significantly. As a consequence, substitution of capital for labor and relocation of production to low cost countries became even more attractive than before. Unemployment remained constant at best. At worst people got laid off.
} 
holics to work less and hedonists to work more, with the overall effect of an increased aggregate labor supply and a lower wage rate. We are now looking at restrictions on individual labor supply that prevent the amount of labor supplied by hedonists to go up. Then more importance or power of workaholics leads to a decrease of aggregate labor supply. More importantly, we find:

Proposition 5 A binding (quantitative) restriction on individual labor supply can be beneficial to all members of population I.

For a comparison between a model with and without binding restrictions on individual labor supply, we start with an equilibrium of the basic model of sections 3 and 4 , with $k_{1}>k_{2}, \alpha=\alpha^{\prime}$ and $l_{1}^{h}<l_{2}^{h}$ where according to (16),

$$
l_{2}^{h}=\left(1-2\left(1-\alpha^{\prime}\right)\left(1-k_{2}\right)\right) T .
$$

We are interested in the equilibrium allocation and welfare at $\alpha>\alpha^{\prime}$ when the labor supply of second household members is restricted by its $\alpha^{\prime}$-equilibrium level, that is

$$
l_{2}^{h} \leq\left(1-2\left(1-\alpha^{\prime}\right)\left(1-k_{2}\right)\right) T
$$

Without this restriction, there would be pressure on second household members to supply more labor as $\alpha$ increases, as exhibited by (16). With the restriction, their labor supply is frozen at the $\alpha^{\prime}$-equilibrium level given by (23). Let

$$
\begin{aligned}
& a=\alpha+(1-\alpha) k_{2}=k_{2}+\alpha\left(1-k_{2}\right)=1-(1-\alpha)\left(1-k_{2}\right) ; \\
& a^{\prime}=\alpha^{\prime}+\left(1-\alpha^{\prime}\right) k_{2}=k_{2}+\alpha^{\prime}\left(1-k_{2}\right)=1-\left(1-\alpha^{\prime}\right)\left(1-k_{2}\right) \text {. }
\end{aligned}
$$

The first order conditions for the household's optimal decision and (23) yield

$$
\begin{aligned}
\lambda c_{1}^{h} & =\alpha k_{1} / a \\
\lambda c_{2}^{h} & =(1-\alpha) k_{2} / a
\end{aligned}
$$




$$
\begin{aligned}
\lambda w l_{1}^{h} & =\lambda w T-\alpha\left(1-k_{1}\right) / a \\
\lambda w l_{2}^{h} & =\lambda w T-\lambda 2 w\left(1-\alpha^{\prime}\right)\left(1-k_{2}\right) T \\
\text { and } & \\
w & =\frac{\left(\alpha k_{1}+(1-\alpha) k_{2}\right) w}{-\alpha\left(1-k_{1}\right)+2 \lambda a w T\left(1-\left(1-\alpha^{\prime}\right)\left(1-k_{2}\right)\right)} .
\end{aligned}
$$

It follows $\lambda=\left(2 a^{\prime} w T\right)^{-1}$ and

$$
\begin{aligned}
c_{1}^{h} & =2\left(a^{\prime} / a\right) \alpha k_{1} w T \\
c_{2}^{h} & =2\left(a^{\prime} / a\right)(1-\alpha) k_{2} w T ; \\
l_{1}^{h} & =T-2\left(a^{\prime} / a\right) \alpha\left(1-k_{1}\right) T \\
l_{2}^{h} & =T-2\left(1-\alpha^{\prime}\right)\left(1-k_{2}\right) T \\
w & =\frac{\beta}{1+2 n\left(1-\left(a^{\prime} / a\right) \alpha\left(1-k_{1}\right)-\left(1-\alpha^{\prime}\right)\left(1-k_{2}\right)\right) T} .
\end{aligned}
$$

Substituting (29) in (25) and (26) yields

$$
\begin{aligned}
c_{1}^{h} & =\frac{\beta \alpha k_{1}}{1 /\left(2 a^{\prime} T\right)+n\left(k_{2}+\alpha\left(k_{1}-k_{2}\right)\right)} ; \\
c_{2}^{h} & =\frac{\beta(1-\alpha) k_{2}}{1 /\left(2 a^{\prime} T\right)+n\left(k_{2}+\alpha\left(k_{1}-k_{2}\right)\right)} .
\end{aligned}
$$

Let us first compare situation $\alpha>\alpha^{\prime}$ with that of $\alpha=\alpha^{\prime}$ under the restriction (24). The second members' labor supply remains constant, whereas the first members' labor supply decreases as $\alpha$ increases. Hence, aggregate labor supply is reduced and the wage rate goes up. Moreover, first household members consume more and second household members consume less. Hence, with the restriction on labor supply in place, first household members are once again clear gainers and second household members remain clear losers from a global sociological change that puts more weight on first household members.

Let us compare next the situation at $\alpha>\alpha^{\prime}$ with and without the restriction. Without the restriction, aggregate labor supply is higher at $\alpha>\alpha^{\prime}$ than at $\alpha=\alpha^{\prime}$, whereas with the restriction it is less. In either case, the 
first household member supplies less labor as $\alpha$ increases, but this negative response is weaker with the restriction. At $\alpha>\alpha^{\prime}$, all household members consume less of the composite good with the restriction than without it, as if in the first case the total time available to each household member were scaled down by the factor $a^{\prime} / a$. Let $\Delta U_{i}^{h}$ denote the difference of the equilibrium utility without and with the restriction. Clearly, $\Delta U_{1}^{h}=\Delta U_{2}^{h}=0$ at $\alpha=\alpha^{\prime}$. Further

$$
\begin{aligned}
\Delta U_{1}^{h}= & k_{1} \ln \left[1 /(2 T)+n\left(k_{2}+\alpha\left(k_{1}-k_{2}\right)\right)\right] \\
& -k_{1} \ln \left[1 /\left(2 a^{\prime} T\right)+n\left(k_{2}+\alpha\left(k_{1}-k_{2}\right)\right)\right] \\
& +\left(1-k_{1}\right) \ln a^{\prime}-\left(1-k_{1}\right) \ln a, \\
\Delta U_{2}^{h}= & k_{2} \ln \left[1 /(2 T)+n\left(k_{2}+\alpha\left(k_{1}-k_{2}\right)\right)\right] \\
& -k_{2} \ln \left[1 /\left(2 a^{\prime} T\right)+n\left(k_{2}+\alpha\left(k_{1}-k_{2}\right)\right)\right] \\
& +\left(1-k_{2}\right) \ln (1-\alpha)-\left(1-k_{2}\right) \ln \left(1-\alpha^{\prime}\right),
\end{aligned}
$$

which implies $\partial \Delta U_{1}^{h} / \partial \alpha<0$ and $\partial \Delta U_{2}^{h} / \partial \alpha<0$. This shows that all household members benefit from the restriction. On the other hand, shareholders and the government suffer from it. The assertion of the proposition has been demonstrated.

\subsection{Distribution of Profits to Households}

So far we have assumed that industry profits accrue to an unspecified leisure class or are siphoned off and used by the government in a non-distortionary fashion. Now we are considering the opposite case where the households of population $I$ own the entire industry. For simplicity we might assume that the shares of the entire industry are held by a single investment fund, and that each household $h$ owns a proportion $\theta^{h} \geq 0$ of that fund, with $\sum_{h} \theta^{h}=1$. Then, if the industry profit is $\pi$, household $h$ receives capital or dividend income $\theta^{h} \pi$ in addition to labor income. More generally, we 
might assume that there exist finitely many firms labelled $j=1, \ldots, m$ with respective profits $\pi_{j}$. Household $h$ owns a proportion $\theta_{j}^{h} \geq 0$ of firm $j$ and receives capital income (dividend payment, profit share) $\theta_{j}^{h} \pi_{j}$ from the firm. The household's total capital income is $\sum_{j} \theta_{j}^{h} \pi_{j}$. For each firm $j, \sum_{h} \theta_{j}^{h}=1$. In any case, when the households own the industry and receive capital income in addition to labor income, the analysis becomes more tedious and it may prove impossible to determine the equilibrium values explicitly. On the other hand, we are now dealing with a closed model of the economy, and the first welfare theorem applies even with positive externalities and efficient collective household decisions. This has been shown for pure exchange economies in Haller (2000). The argument readily generalizes to economies with private ownership of production. Hence, in stark contrast to Proposition 4, we find:

Proposition 6 Suppose that the households in population I own the entire industry. If a global sociological change benefits (harms) one sociological group, then it harms (benefits) the other one. If a local sociological change benefits (harms) one sociological group, then it harms (benefits) some member of the other group.

The preceding proposition is reminiscent of the differential impact of pecuniary and non-pecuniary externalities in a general equilibrium model. While the former do not destroy Pareto-efficiency, the latter do it in general unless they are internalized. In our model, non-pecuniary externalities occur only at the household level, and are internalized by efficient collective decisions within households. Thus, the first welfare theorem still applies. 


\section{Implications}

In this section, we discuss how our findings may be used to explain and assess recent trends in the length of working hours in industrialized countries. We first summarize the most important developments.

First, there have been strong attempts to reduce the regular work week in Europe, in particular in traditional manufacturing industries. In Germany, by way of collective bargaining, and in France, by law, the regular work week has been reduced to 35 hours. Although the work day and work week for low income workers in the US have also declined by a relatively small amount since mid-century, working hours per week and per year have strongly diverged between US and Germany or France over the last decades (see e.g. Freeman (1993) and Layard (2003)).

Second, whereas a century ago the lowest paid workers worked the longest day, today it is the highest paid workers who work the longest day (see Costa (2000)). Coleman and Pencavel (1993a, 1993b) find that increases in weekly hours of work for the college educated and declines for those with a high school education or less have been ongoing since 1940 .

Third, the service sector has gained a larger share in the economy in terms of value added and employment at the expense of the traditional industries. Within the service sector, certain industries, such as investment banking, software development or management consulting have experienced above average growth in employment. Such industries typically have a large proportion of high-skilled employees (as reported by McKinsey Global Institute (1997), e.g.). From this fact, and the findings of Coleman and Pencavel (1993a, 1993b) and Costa (2000) regarding increases in weekly hours of work for the college educated, we can conclude that over the past decades the fraction of people working considerably more than the standard hours 
per week for low-skilled workers has increased in a variety of service industries.

These trends can be related to our results as follows. We have found that a binding restriction on individual labor supply can be beneficial to all members of the working population. Restrictions on labor supply can prevent workaholics to exert too much pressure on their hedonistic partners to work more. A restriction on individual labor supply supports a higher wage rate and improves welfare at the working class population. Our analysis suggests that the working class in France and Germany have been able to increase their utility by restricting labor supply.

Why a similar effect has not been observed in the US might be explained by two differences between labor markets in the US and Europe (see e.g. Freeman 1993). First, labor has much less power to force regulation in the US compared to continental Europe and second, profit income is more widely dispersed in the US than in continental Europe, and hence the separation between a working and a leisure class is less pronounced in the US which, in turn, may make welfare effects of labor supply constraint more ambiguous.

The interpretation above suggests that income per capita is higher in the US, but welfare of the working class might be higher in Germany or France. Recently, Layard (2003) has suggested that people's rivalry over income, but not over leisure, induces developed societies such as the US to work too hard in order to consume more material goods. Our result points to an alternative interpretation. In some developed countries people might work too much since they have not been able to restrict collectively working hours which would improve the welfare of the working class.

However, the story is not complete by looking only at working hours. In Germany and France collective or governmental wage setting has contributed 
to the emergence and persistence of unemployment. ${ }^{6}$ Although, we have not formally examined unemployment and real wage rigidity, the model can be extended in a straightforward way to such settings. While unemployed persons are harmed by restricting working hours and above market clearing wages in our extended model, employed individuals may benefit twice from such joint interventions in the labor market, in particular if they are hedonists. The joint determination of working hours and real wages create two insider and outsider subclasses among the working class, depending on whether an individual is employed, and whether an individual is a hedonist or a workaholic. The insider subclass consisting of hedonists benefits most by creating negative externalities for the unemployed and the leisure class.

Concerning the second and third trend, our analysis suggests that ceteris paribus, the surge in the number of "new workaholics" employed in some of the expanding service industries described above, may harm not only others, but might be detrimental to the workaholics themselves, unless a significant part of their income is directly linked to the profits of the respective industries through stock ownership, stock options, or bonuses. The latter stipulation provides a rationale, in addition to the usual incentive reasons, for compensation schemes that are partially based on firm performance. Of course, these hard workers may simply work more because they are better qualified and, therefore, are paid a higher hourly wage. A formal analysis of the implications of differentiated human capital would necessitate a ramification of the model. This is left to future research.

\footnotetext{
${ }^{6}$ Survey and detailed accounts of labor market factors as root causes of the unemployment problem in Europe can be found e.g. in Layard, Jackman, and Nickell (1991), Bean (1994), Krugman (1994), Alogoskoufis, Bean, Bertola, Cohen, Dolado and Saint-Paul (1996), Lindbeck (1996), Siebert (1997), Nickell (1997) and Saint-Paul (2000).
} 


\section{Conclusions}

We interpreted a change of household preferences in the form of a shift of the utilitarian weights in the household objective function as a sociological change. We found that such a change causes spillovers on other households. The size and sign of these spillovers depend on whether sociological changes are local or global, intra-household externalities are fixed or variable, individual labor supply restrictions are binding or not, and whether working households own the production sector or not. The spillovers occur through the labor market. As a rule, they occur only when the two household members differ in their individual preferences, so that they can be labelled as "workaholic" and "hedonistic". Otherwise, the sociological change within a household does not affect the aggregate labor supply of the household (as inspection of (17) and (21) plus (22) shows) and the labor market is shut down as channel for spillovers.

It is common and sometimes, though not always, quite natural and productive to distinguish the two partners in a household by gender. Such a distinction is immaterial for the current analysis. However, the reader is free to attribute specific genders to the "workaholics" and "hedonists" of our model, if he or she so desires.

The framework may also be extended by considering richer family structures. In particular, incorporating children and home production is a fruitful line for future research. For instance, the presence of children likely tends to increase the amount and diversity of externalities generated in a household while leisure time will become more scarce. As a consequence, it might be even more advantageous for the working class to restrict work hours. 


\section{References}

Alogoskoufis, G., C. Bean, G. Bertola, D. Cohen, J. Dolado, G. SaintPaul: "Unemployment: Choices for Europe", Centre for Economic Policy Research, 1996.

Auerbach, A.J.: "The Theory of Excess Burden and Optimal Taxation," Ch. 5 in A.J. Auerbach and M. Feldstein (eds.), Handbook of Public Economics, Vol. I., Elsevier Science Publishers B.V. (North-Holland): Amsterdam, 1985.

Bean, C.: "European Unemployment: A Survey", Journal of Economic Literature, Vol. XXXII , (1994), 573-619.

Börsch-Supan, A.: "Reduction of Working Time: Does it Decrease Unemployment?", mimeo, 2003.

Burda, M., and P. Weil: "Blue Laws", mimeo, Humboldt-Universität zu Berlin, 1999.

Chiappori, P.-A.: "Rational Household Labor Supply," Econometrica 56 (1988), 63-89.

Chiappori, P.-A.: "Collective Labor Supply and Welfare," Journal of Political Economy 100 (1992), 437-467.

Chiappori, P.-A., B. Fortin and G. Lacroix: "Marriage Market, Divorce Legislation and Household Labor Supply," Journal of Political Economy 110 (February) (2002), 37-72.

Clemenz, G.: "Non-sequential Consumer Search and the Consequences of a Deregulation of Trading Hours", European Economic Review 34 (1990), 1323-1337. 
Coleman, M.T., and J. Pencavel: "Changes in Work Hours of Male Employees 1940-1988", Industrial and Labor Relations Review 46 (January) (1993a), 262-283.

Coleman, M.T., and J. Pencavel: "Trends in Market Work Behavior of Women since 1940", Industrial and Labor Relations Review 46 (July) (1993b), 653-76.

Costa, D.L.: "The Wage and the Length of the Work Day: From the 1890s to 1991", Journal of Labor Economics 18 (2000), 156-181.

Entorf, H., H. König and W. Pohlmeier: "Labor Utilization and Nonwage Labor Costs in a Disequilibrium Macro Framework", Scandinavian Journal of Economics 94 (1) (1992), 71-83.

Freeman, R.B. (Ed.): "Working Under Different Rules", A National Bureau of Economic Research Project Report, Russel Sage Foundation, New York 1993.

Gersbach, H., and H. Haller: "Collective Decisions and Competitive Markets," Review of Economic Studies, 68 (2001), 347-368.

Haller, H.: "Household Decisions and Equilibrium Efficiency", International Economic Review 41 (November 2000), 835-847.

Hunt, J.: "Hours Reduction as Work Sharing", Brookings Papers on Economic Activity 1 (1998), 339-381.

Krugman, P.: "Past and Prospective Causes of High Unemployment", in Reducing Unemployment: Current Issues and Policy Options, A Symposium Sponsored by the Federal Reserve Bank of Kansas City, Wyoming (1994), 49-80.

Layard, R., S. Nickell and R. Jackman: "Unemployment", Oxford University Press, Oxford (1991). 
Layard, R.: "Happiness - Has Social Science a Clue?" Lionel Robbins Memorial Lectures 2003, Centre for Economic Performance, London School of Economics.

Lindbeck, A.: "The West European Employment", Weltwirtschaftliches Archiv (1996), 609-637.

McKinsey Global Institute: "Removing Barriers to Growth and Employment in France and Germany", McKinsey Global Institute (1997).

Putnam, R.: "Bowling Alone: America's Declining Social Capital", Journal of Democracy 6 (1995), 65-78.

Saint-Paul, G.: The Political Economy of Labour Market Institutions. Oxford University Press (2000).

Siebert, H.: At the Root of Unemployment in Europe", Journal of Economic Perspectives 11 (1997), 37-55.

Weiss, Y.: "Synchronization of Work Schedules", International Economic Review 37 (1996), 157-179. 